Check for updates

Cite this: RSC Adv., 2019, 9, 38454

Received 31st July 2019

Accepted 19th October 2019

DOI: $10.1039 / \mathrm{c} 9 \mathrm{ra0} 9904 \mathrm{k}$

rsc.li/rsc-advances

\section{Experimental and theoretical study of $\mathrm{CO}_{2}$ adsorption by activated clay using statistical physics modeling}

\author{
Hedi Jedli, (D) *a Chaker Briki, ${ }^{a}$ Amani Chrouda, ${ }^{\text {b }}$ Jihed Brahmi, ${ }^{c}$ Amel Abassi, ${ }^{d}$ \\ Abdessalem Jbara, ${ }^{e}$ Khalifa Slimi ${ }^{e}$ and Abdelmajid Jemni ${ }^{a}$
}

\begin{abstract}
The objective of this paper was to study $\mathrm{CO}_{2}$ adsorption on activated clay in the framework of geological storage. The activation of clay was characterized via scanning electron microscopy, $\mathrm{N}_{2}$ adsorptiondesorption isotherms, and $\mathrm{X}$-ray diffraction. The adsorption isotherms were generated at different temperatures, namely, 298 K, 323 K, and $353 \mathrm{~K}$. Based on the experimental result, a new model was simulated and interpreted using a multi-layer model with two interaction energies. The physicochemical parameters that described the $\mathrm{CO}_{2}$ adsorption process were determined by physical statistical formalism. The characteristic parameters of the $\mathrm{CO}_{2}$ adsorption isotherm such as the number of carbon dioxide molecules per site (n), the receptor site densities (NM), and the energetic parameters were investigated. In addition, the thermodynamic functions that governed the adsorption process such as the internal energy, entropy, and Gibbs free energy were determined by a statistical physics model. Thus, the results showed that $\mathrm{CO}_{2}$ adsorption on activated clay was spontaneous and exothermic in nature.
\end{abstract}

\section{Introduction}

Carbon dioxide is considered a major greenhouse gas and the cause of climate change. ${ }^{1}$ The IPCC estimates that $\mathrm{CO}_{2}$ concentration levels may increase to 570 ppm by the year 2100, causing an increase in the global average temperature of about $1.9^{\circ} \mathrm{C}^{2}$ One of the solutions to reduce carbon dioxide emissions from fixed-point sources is the development of $\mathrm{CO}_{2}$ capture and storage technologies. In order to sequestrate $\mathrm{CO}_{2}$ from fuel gases, various techniques have been studied such as chemical adsorption, $^{3}$ absorption ${ }^{4}$ and use of membranes. ${ }^{5}$ Solid adsorption is the most promising for $\mathrm{CO}_{2}$ capture because of its low energy requirements, cost effectiveness, and ease of use at a variety of pressures and temperatures. ${ }^{6}$ Many different adsorbents can be used for this purpose such as clay, activated carbon zeolites, mesoporous silica, and organo-metallic structures. In this context, clay is considered a natural material for $\mathrm{CO}_{2}$ adsorption. $\mathrm{CO}_{2}$ adsorption with bentonitic clay minerals

${ }^{a}$ University of Monastir, National Engineering School of Monastir, Laboratory of Studies of Thermal Systems and Energy, LR99ES31, 5019, Monastir, Tunisia. E-mail: jedli.hedi@gmail.com

${ }^{b}$ Department of Chemistry, College of Science at Zulfi, Majmaah University, Zulfi 11932, Saudi Arabia

'University of Monastir, Laboratoire de Physico-chimie des Matériaux, Faculté des Sciences de Monastir, Avenue de l'Environnement, 5019 Monastir, Tunisia

${ }^{d}$ Physics Department Faculty of Science and Arts, Jouf University, Tabarjal, Saudi Arabia

${ }^{e}$ University of Sousse, Higher Institute of Transportation and Logistics, P. O. Box 247, Riyadh City, 4023, Sousse, Tunisia from Patagonia was studied by Venaruzzo et al. (2002). ${ }^{7}$ Equilibrium adsorption of the gas was measured at $25{ }^{\circ} \mathrm{C}$ and characterized by chemical analysis, X-ray diffraction, and $\mathrm{N}_{2}$ adsorption-desorption isotherms. This study indicated that the increase in the gas adsorption with bentonitic clay minerals was attributed to textural and structural properties. Chen et al. $(2015)^{8}$ discussed the mechanism of $\mathrm{CO}_{2}$ adsorption by kaolinite via XRD, FTIR spectroscopy, and $\mathrm{CO}_{2}$ adsorption isotherm measurements. The $\mathrm{CO}_{2}$ adsorption performance of the sample was assessed on the basis of the changes in its weight. Also, the $\mathrm{CO}_{2}$ adsorption isotherm was measured using an ASAP 2020c (Micromeritics) static volumetric apparatus. Lyu et al. $(2018)^{9}$ investigated the effect of $\mathrm{CO}_{2}$ adsorption on the mechanical properties of clay shale in several high-pressure containers. This study provided actual experimental data on the adsorption properties of shale with carbon dioxide. Jedli et al. (2016) ${ }^{10}$ compared the effects of $\mathrm{CO}_{2}$ adsorption on various samples such as clay, evaporates, and sandstone. The adsorbents were reacted on a batch reactor and characterized thoroughly via X-ray diffraction (XRD), scanning electron microscopy (SEM), Fourier transform infrared spectroscopy (FTIR), and nitrogen adsorption. The adsorption isotherms were measured at different temperatures and modeled with the Langmuir model. The main aim of this study, therefore, was to investigate the adsorption process of carbon dioxide on a solid surface, especially activated clay. In this context, an experiment was performed to investigate the $\mathrm{CO}_{2}$ adsorption process on activated clay. In fact, the adsorbent was characterized thoroughly via XRD (X-ray diffraction), SEM (scanning electron 
microscopy), and nitrogen adsorption desorption. The experimental data was modeled with statistical physics processing at 25,50 , and $75{ }^{\circ} \mathrm{C}$. The fitting results were used to discuss the thermodynamics parameters for each adsorption isotherm type. Moreover, a detailed study of the main intrinsic features of the adsorbent was performed. Additionally, a detailed study of the physicochemical parameters of the adsorbent was established.

\section{Experimental details}

\subsection{Materials and methods}

The experimental device is presented in Fig. 1. It was essentially composed of a batch reactor with a total volume of $232 \mathrm{~cm}^{3}$, a manometer, electric heating, and a $\mathrm{CO}_{2}$ supply bottle (VMS-A $\mathrm{S} 40)$. The raw clay was collected from a real site located in southern Tunisia and treated with $\mathrm{H}_{2} \mathrm{SO}_{4}$ solution $(3 \mathrm{M}) \cdot{ }^{11}$ Characterization techniques were used to describe the sample at different observation scales. X-ray diffraction was performed on a "Philips MPD1880-PW1710" diffractometer with $\lambda_{\mathrm{CuK} \alpha}$ radiation in the $2-80^{\circ}$ interval with a step size of $0.02^{\circ}$ and a counting time of $20 \mathrm{~s}$ per step. The quantification phase was performed on one sample by the Rietveld method (R-QPA) using a PANalytical X'Pert High-Score Plus Program. The surface morphologies of the adsorbent were observed by a Thermo Fisher FEI Q250 scanning electron microscope. The porous textural characterizations were determined using an ASAP 2020 micromeritics analyzer. The specific BET surface area and pore size distribution were obtained using the adsorption/ desorption isotherms of nitrogen vapor at $77 \mathrm{~K}$.

\subsection{Characterization of adsorbent}

Table 1 shows the chemical composition of the activated clay determined by X-ray fluorescence (XRF). The XRF indicated the presence of silica $\left(\mathrm{SiO}_{2}\right)$, aluminum $\left(\mathrm{Al}_{2} \mathrm{O}_{3}\right)$, and iron oxide $\left(\mathrm{Fe}_{2} \mathrm{O}_{3}\right)$ as main constituents, as well as traces of other oxides such as magnesium oxide $(\mathrm{MgO})$, calcium oxide $(\mathrm{CaO})$, and potassium oxide $\left(\mathrm{K}_{2} \mathrm{O}\right)$. From the XRD diffractograms of activated clay (Fig. 2), the characteristic reflections located at $4.45 \AA$ and

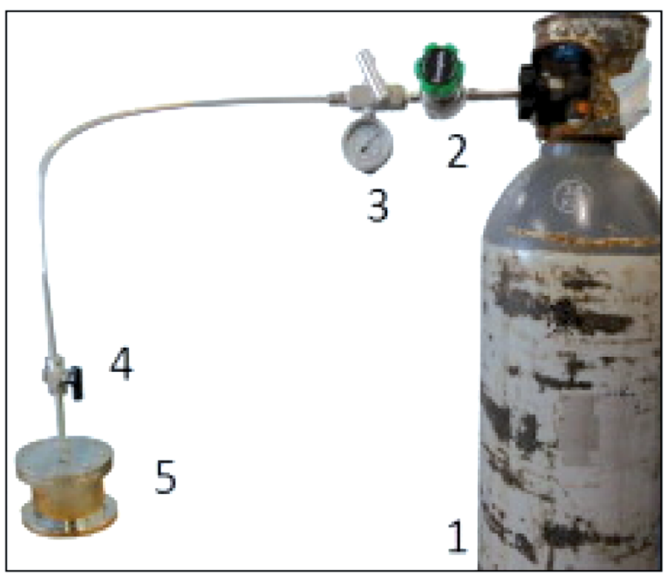

Fig. 1 Schematic of the experimental study (1) gas cylinder, (2) pressure regulator, (3) pressure indicator, (4) needle valves, and (5) batch reactor.
$3.33 \AA$ were assigned to illite, whereas kaolinite was found at 7.51, $3.78,2.56$, and $2.48 \AA$. The characteristic reflections of dolomite were observed at $2.88 \AA$ and those of quartz at 3.33 and $1.87 \AA$. The $\mathrm{N}_{2}$ adsorption-desorption isotherms of activated clay corresponded to a typical type IV isotherm, characteristic of a mesoporous material (Fig. 3). The hysteresis loop for the sample was similar to type $\mathrm{H} 3$, which was typical of agglomerates with platelike particles containing slit-shaped pores. The textural properties, including the BET surface areas, pore volumes, and pore sizes of activated treated clay are presented in Table 2 . The surface area and pore volume of the clay sample were $24.68 \mathrm{~cm}^{2}$ $\mathrm{g}^{-1}$ and $0.064 \mathrm{~cm}^{2} \mathrm{~g}^{-1}$, respectively, indicating that activated clay exhibited a low porosity. The scanning electron micrographs of the sample are provided in Fig. 4. The SEM showed a different particle morphology. In fact, the adsorbent presented a stratified form containing stacked flakes in the form of agglomerates, which displayed irregular and angular edges. The adsorption isotherms on activated clay at 25,50 , and $75{ }^{\circ} \mathrm{C}$ are depicted in Fig. 5. As expected, these isotherms were expressed as a function of the amount adsorbed and the pressure. The adsorption capacity increased with the increase in the pressure. In fact, an increase in the adsorption temperature led to a reduction in the amount of carbon dioxide adsorbent.

\section{Modeling by statistical physics of $\mathrm{CO}_{2}$ adsorption isotherms}

\subsection{Adsorption modeling}

The analytical expression used for the adsorption isotherms was based on a statistical physics approach. The statistical physics treatment was used for the gas physical states of the adsorbate. Furthermore, the interaction between the adsorbed molecules was neglected. ${ }^{12}$ The physical interpretations of the adsorption phenomenon were provided according to the experimental study. For the state of adsorption, the equation used was: ${ }^{13}$

$$
n A+S \leftrightarrow A_{n} S
$$

where $n, S$ and $A_{n} S$ are respectively the receptor sites, the number of molecules per site and the formed adsorbateadsorbent complex. In the present study, we used a grand canonical partition function for the interstitial site. This function described each adsorption process for the microscopic states. The receptor site could be empty or occupied by one or more molecules. The grand canonical partition for one receptor site is expressed in the following equation: ${ }^{14}$

$$
z_{\mathrm{gc}}=\sum_{N_{i}} \mathrm{e}^{-\beta\left(-\varepsilon_{i}-\mu\right) N_{i}}
$$

where $\left(-\varepsilon_{i}\right)$ is the receptor site sorption energy, $N_{i}$ is the receptor site occupation state, $\mu$ is the chemical potential, and $\beta$ is defined as $1 / k_{\mathrm{B}} T . T$ is the absolute temperature and $k_{\mathrm{B}}$ is the Boltzmann constant. The relation between the total grand canonical partition function, $Z_{\mathrm{gc}}$, and the NM receptor sites is given by eqn (3):

$$
Z_{\mathrm{gc}}=\left(z_{\mathrm{gc}}\right)^{\mathrm{NM}}
$$


Table 1 Chemical analysis of activated clay

\begin{tabular}{llllllllll}
\hline Element, wt\% & $\mathrm{SiO}_{2}$ & $\mathrm{Al}_{2} \mathrm{O}_{3}$ & $\mathrm{CaO}$ & $\mathrm{Fe}_{2} \mathrm{O}_{3}$ & $\mathrm{Na}_{2} \mathrm{O}$ & $\mathrm{K}_{2} \mathrm{O}$ & $\mathrm{MgO}^{2}$ & $\mathrm{TiO}_{2}$ & $\mathrm{I} . \mathrm{LO}$ \\
Activated clay & 69.87 & 8.23 & 6.72 & 1.84 & 0.14 & 2.48 & 4.02 & 0.10 & 7.78
\end{tabular}

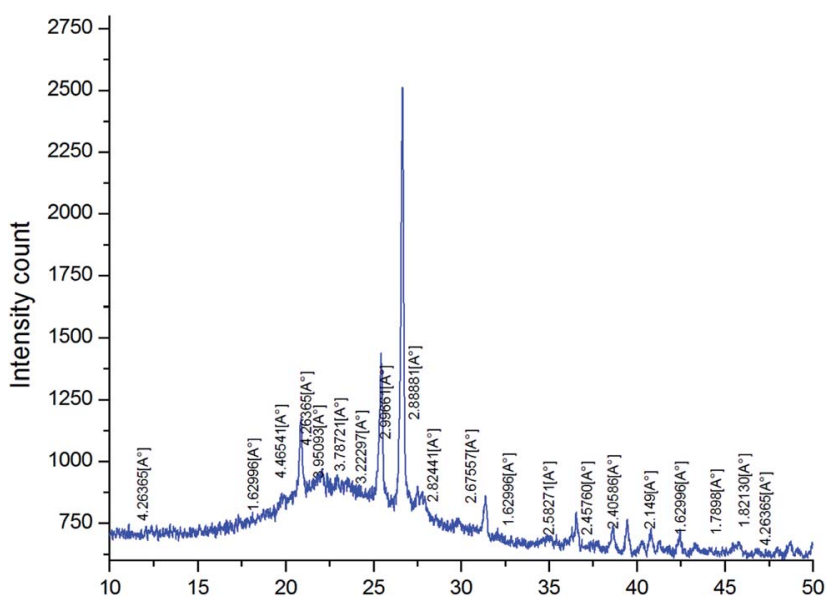

Fig. 2 XRD of activated clay.

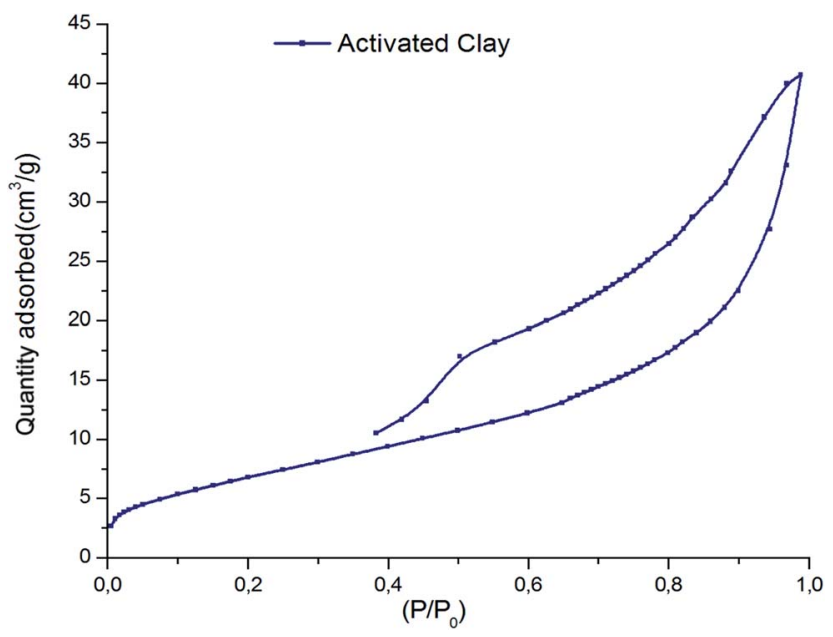

Fig. $3 \quad \mathrm{~N}_{2}$ adsorption-desorption isotherm of activated clay.

The average number of sites can be described as follows: ${ }^{15}$

$$
N_{0}=k_{\mathrm{B}} T \frac{\partial \ln Z_{\mathrm{gc}}}{\partial \mu}=N_{\mathrm{M}} k_{\mathrm{B}} T \frac{\partial \ln z_{\mathrm{gc}}}{\partial \mu}
$$

The average number of the adsorbed molecules is written as follows: ${ }^{16}$

$$
Q=n N_{0}=n N_{\mathrm{M}} \frac{\partial \ln Z_{\mathrm{gc}}}{\partial \mu}=Q_{0} \frac{\partial \ln Z_{\mathrm{gc}}}{\partial \mu}
$$

To develop the multilayer model during the adsorption process, we considered that the mutual interactions between the adsorbate molecules were neglected. Then, the internal degrees of freedom for the gas were neglected. However, the molecules in the first layer $\left(N_{1 \mathrm{M}}\right)$ were adsorbed with $\left(-\varepsilon_{1}\right)$ energy, whereas the molecules in the next $\left(N_{2 \mathrm{M}}\right)$ layers were adsorbed with $\left(-\varepsilon_{2}\right)$ energy, knowing that $\left|\varepsilon_{1}\right|>\left|\varepsilon_{2}\right|>0$. Under these conditions, the global grand canonical partition function was written as:

$$
Z_{\mathrm{gc}}=\left(z_{1 \mathrm{gc}}\right)^{N_{1 \mathrm{M}}}\left(z_{2 \mathrm{gc}}\right)^{N_{2 \mathrm{M}}}
$$

where $z_{1 \mathrm{gc}}$ and $z_{2 \mathrm{gc}}$ are respectively the partition function for site type 1 and 2 . Their expressions are:

$$
\begin{aligned}
& z_{1 \mathrm{gc}}=\sum_{N_{i}=0.1} \mathrm{e}^{-\beta\left(-\varepsilon_{1}-\mu\right) N_{i}}=1+\mathrm{e}^{\beta\left(\mu+\varepsilon_{1}\right)} \\
& z_{2 \mathrm{gc}}=\sum_{N_{i}=0.1} \mathrm{e}^{-\beta\left(-\varepsilon_{2 i}-\mu\right) N_{i}}=1+\mathrm{e}^{\beta\left(\mu+\varepsilon_{2}\right)}
\end{aligned}
$$

where $\left(-\varepsilon_{1}\right)$ and $\left(-\varepsilon_{2}\right)$ are the receptor site desorption energies, $\mathrm{N}_{\mathrm{i}}$ is the receptor site occupation state, $\mu$ is the chemical potential of the adsorbed site, and $\beta$ is expressed by $1 / k_{\mathrm{B}} T . T$ is the temperature in $\mathrm{K}$ and $k_{\mathrm{B}}$ is the Boltzmann constant. During thermodynamic equilibrium, the equality of the different chemical potentials can be written as $\mu_{m}=\mu / n$, where $\mu$ is the chemical potential of the receptor site and $n$ is the number of atoms per site.

Using the first approximation for an ideal gas, $\mu_{m}$ can be expressed as follows: ${ }^{17}$

$$
\mu_{m}=k_{\mathrm{B}} T \ln \frac{N}{Z_{\mathrm{g}}}
$$

where:

$$
Z_{\mathrm{g}}=\frac{\left(2 \pi m k_{\mathrm{B}} T\right)^{3 / 2}}{h^{3}} \frac{T V}{2 \theta_{\text {rot }}}
$$

where $\theta_{\text {rot }}, m, v$, and $h$ are respectively the rotational characteristic temperature, the mass of the adsorbed gas, the volume of the gas, and Planck's constant.

Using eqn (5), the average number of occupied sites was expressed by the following equation:

Table 2 Textural properties for activated clay

\begin{tabular}{llll}
\hline Concentration of $\mathrm{H}_{2} \mathrm{So}_{4}(\mathrm{M})$ & $\begin{array}{l}\text { BET surface } \\
\text { area }\left(\mathrm{m}^{2} \mathrm{~g}^{-1}\right)\end{array}$ & Pore volume $\left(\mathrm{cm}_{3} \mathrm{~g}^{-1}\right)$ & $\begin{array}{l}\text { Pore size } \\
(\AA)\end{array}$ \\
\hline Activated clay & 24.68 & 0.064
\end{tabular}



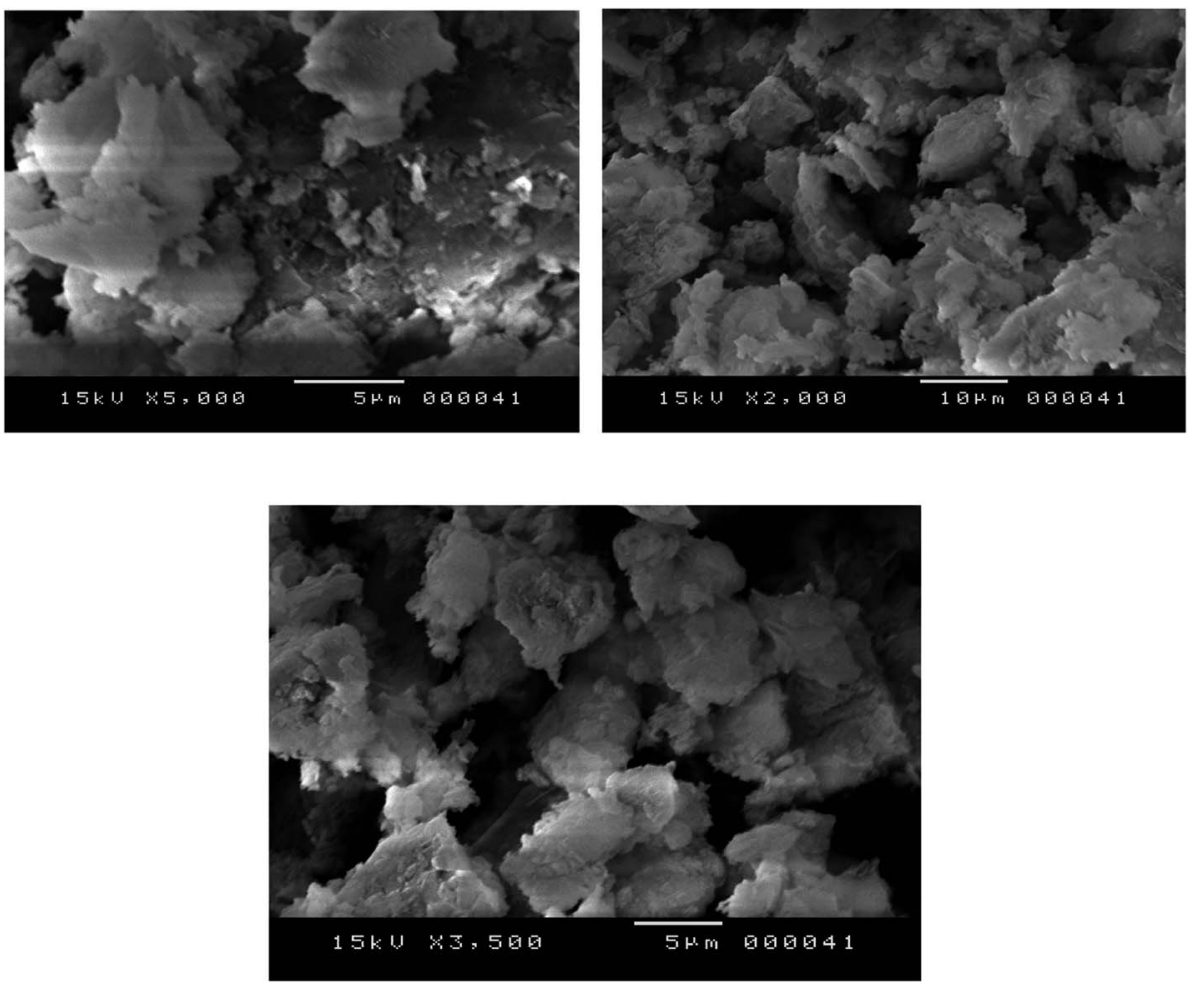

Fig. 4 SEM morphologies of the activated clay.

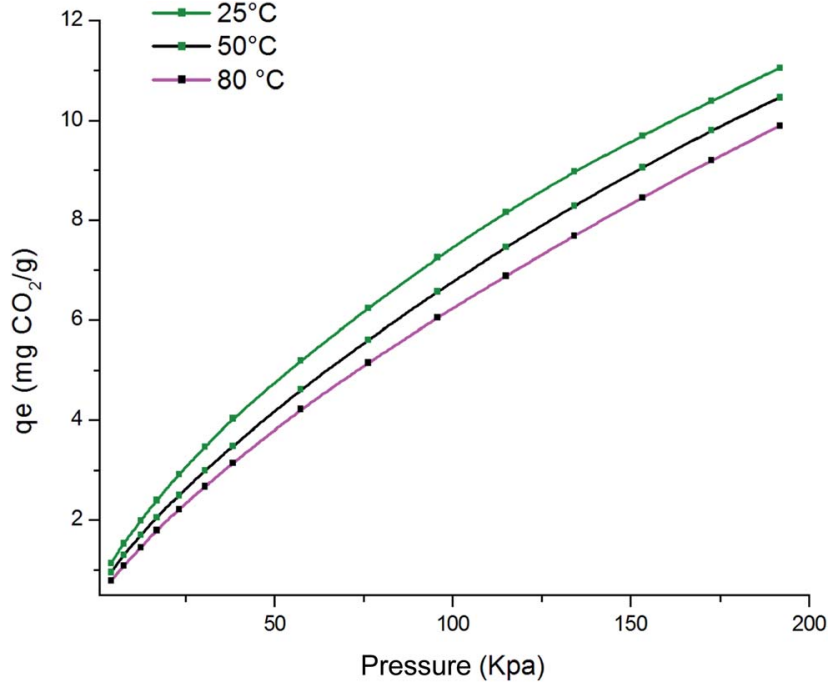

Fig. $5 \mathrm{CO}_{2}$ adsorption isotherms on activated clay.

$$
N_{0}=\frac{N_{1 \mathrm{M}}}{1+\mathrm{e}^{-\beta\left(\mu+\varepsilon_{1}\right)}}+\frac{N_{2 \mathrm{M}}}{1+\mathrm{e}^{-\beta\left(\mu+\varepsilon_{2}\right)}}
$$

where $\varepsilon_{1 \mathrm{~m}}$ and $\varepsilon_{2 \mathrm{~m}}$ are the energies of an adsorbed gas atom on the two different sites, respectively. We can write: $\varepsilon_{1 \mathrm{~m}}=\frac{\varepsilon_{1}}{n_{1}}$ and $\varepsilon_{2 \mathrm{~m}}=\frac{\varepsilon_{2}}{n_{2}}$

Using eqn (7) and the equilibrium conditions related to the chemical potentials, the average number of occupied sites given in eqn (9) becomes:

$$
\begin{aligned}
N_{0} & =\frac{N_{1 \mathrm{M}}}{1+\mathrm{e}^{-\beta\left(\mu_{\mathrm{g}}+\varepsilon_{\mathrm{lm}}\right)^{n_{1}}}}+\frac{N_{2 \mathrm{M}}}{1+\mathrm{e}^{-\beta\left(\mu_{\mathrm{g}}+\varepsilon_{2 \mathrm{~m}}\right)^{n_{2}}}} \\
& =\frac{N_{1 \mathrm{M}}}{1+\mathrm{e}^{-\beta\left(\varepsilon_{\mathrm{Im}}\right)^{n_{1}}}\left(\frac{z_{\mathrm{g}}}{\beta P}\right)^{n_{1}}}+\frac{N_{2 \mathrm{M}}}{1+\mathrm{e}^{-\beta\left(\varepsilon_{2 \mathrm{~m}}\right)^{n_{2}}}\left(\frac{z_{\mathrm{g}}}{\beta P}\right)^{n_{2}}}
\end{aligned}
$$

If we take $P=k_{\mathrm{B}} T Z_{\mathrm{gtr}} \mathrm{e}^{\beta \varepsilon_{\mathrm{m}}}$, we obtain an average number of occupied sites at half $N_{01}=N_{1 \mathrm{M} / 2}$ and $N_{02}=N_{2 \mathrm{M} / 2}$. We then noted that $P_{1}=k_{\mathrm{B}} T Z_{\mathrm{gtr}} \mathrm{e}^{-\beta \varepsilon_{1 \mathrm{~m}}}$ and $P_{2}=k_{\mathrm{B}} T Z_{\mathrm{gtr}} \mathrm{e}^{-\beta \varepsilon_{2 \mathrm{~m}}}$, which represented the pressure at half-saturation. This corresponded respectively to the first and the second type of sites. $n_{1}$ and $n_{2}$ are the number of atoms per site. The average number of occupied sites is written as follows:

$$
N_{0}=N_{01}+N_{02}=\frac{N_{1 \mathrm{M}}}{1+\left(\frac{P_{1}}{P}\right)^{n_{1}}}+\frac{N_{2 \mathrm{M}}}{1+\left(\frac{P_{2}}{P}\right)^{n_{2}}}
$$

Using eqn (1) and the number of average occupation site, $N_{0}$, the average number of remaining adsorbed molecules is:

$$
N_{\mathrm{a}}=n_{1} N_{01}+n_{2} N_{02}
$$

The expression for the number of remaining adsorbed gas molecules as a function of pressure is written as follows:

$$
N_{\mathrm{a}}=\frac{n_{1} N_{1 \mathrm{M}}}{1+\left(\frac{P_{1}}{P}\right)^{n_{1}}}+\frac{n_{1} N_{2 \mathrm{M}}}{1+\left(\frac{P_{2}}{P}\right)^{n_{2}}}
$$


The experimental adsorbed quantity, $Q_{s}$, indicates the number of $\mathrm{CO}_{2}$ atoms per unit formula. In our model, there were two types of sites that adsorbed two different quantities, $n_{1}$ and $n_{2}$, on $N_{1 \mathrm{M}}$ and $N_{2 \mathrm{M}}$. In fact, we took the average between $n_{1}$ and $n_{2}$ weighted by $N_{1 \mathrm{M}}$ and $N_{2 \mathrm{M}}$.

$$
Q_{\mathrm{s}}=Q_{\mathrm{s} 1}+Q_{\mathrm{s} 2}
$$

where

$$
Q_{\mathrm{S} 1}=\frac{n_{1} N_{1 \mathrm{M}}}{N_{1 \mathrm{M}}+N_{1 \mathrm{M}} 1+\left(\frac{P_{1}}{P}\right)^{n_{1}}} \frac{1}{1+\left(\frac{P_{1}}{P}\right)^{n_{1}}}=\frac{Q_{\text {sat } 1}}{1+\left(\frac{P_{1}}{P}\right)^{n_{1}}}
$$

$$
Q_{\mathrm{S} 2}=\frac{n_{2} N_{2 \mathrm{M}}}{N_{2 \mathrm{M}}+N_{2 \mathrm{M}} 1+\left(\frac{P_{2}}{P}\right)^{n_{2}}} \frac{1}{1+\left(\frac{P_{2}}{P}\right)^{n_{2}}}=\frac{Q_{\mathrm{sat} 2}}{1+\left(\frac{P_{2}}{P}\right)^{n_{2}}}
$$

The analytical model expression that fitted the experimental isotherms was:

$$
Q_{\mathrm{s}}=\frac{Q_{\mathrm{sat} 1}}{1+\left(\frac{P_{1}}{P}\right)^{n_{1}}}+\frac{Q_{\mathrm{sat} 2}}{1+\left(\frac{P_{2}}{P}\right)^{n_{2}}}
$$

The final expression for the average number of adsorbed molecules (first model, namely, Model 1) can be expressed by the following equation: ${ }^{16}$ clay showed a saturation phenomenon at high pressures. The experimental data was used in the simulation process with different theoretical models based on a statistical physics treatment. To obtain the different parameters for the model, several iterations were used for all of experimental results. Classical and non-classical models were evaluated such as Langmuir, BET, Hill (1), and Hill (2). ${ }^{\mathbf{1 8 , 1 9}}$ In addition to the first adsorption layer, the adsorption phenomenon was assumed to also increase a number of layers. Thus, the classical Hill model and the double layer Hill model, which respectively considered one energy $\left(-\varepsilon_{1}\right)$ (Model 2$)$ and two energies $\left(-\varepsilon_{1}\right)$ and $\left(-\varepsilon_{2}\right)$ (Model 3$)^{20}$ were tested. The most suitable model was determined according to the correlation coefficient, $R_{2}$. Table 3 present the adjustment coefficient values for the different models. The fit of the experimental adsorption isotherms for activated clay at $298 \mathrm{~K}, 323 \mathrm{~K}$, and $348 \mathrm{~K}$ showed that the model correlated well with the experimental data as illustrated in Fig. 6.

\section{Results}

\subsection{Steric parameters}

The monolayer model with two types of sites was suitable for analyzing the experimental adsorption isotherms. The model parameters gave characteristics on the number of desorbed atoms per site, the density of the receptor sites, and the desorption energies. These parameters were classified into two categories. The number of steric atoms by site was $n_{1}$ and $n_{2}$ and receptor site densities were $\mathrm{NM}_{1}$ and $\mathrm{NM}_{2}$. Energy parameters $P_{1}$ and $P_{2}$ gave the desorption energy, which characterized the bond between the atoms and receptor sites. The values for the adjusted parameters are provided in Table 4 .

$$
Q=\left(n N_{\mathrm{M}}\right)\left(\frac{\left(\frac{P}{P_{1}}\right)^{n}+2 \frac{\left(\frac{P}{P_{1}}\right)^{n}\left(\frac{P}{P_{2}}\right)^{n}\left(1-\left(\frac{P}{P_{2}}\right)^{n N_{\mathrm{L}}}\right)}{\left(1-\left(\frac{P}{P_{2}}\right)^{n}\right)}-\frac{\left(\frac{P}{P_{1}}\right)^{n}\left(\frac{P}{P_{2}}\right)^{n}\left(\frac{P}{P_{2}}\right)^{n N_{\mathrm{L}}} N_{\mathrm{L}}}{\left(1-\left(\frac{P}{P_{2}}\right)^{n}\right)}+\frac{\left(\frac{P}{P_{1}}\right)^{n}\left(\frac{P}{P_{2}}\right)^{2 n}\left(\frac{P}{P_{2}}\right)^{n N_{\mathrm{L}}} N_{\mathrm{L}}}{\left(1-\left(\frac{P}{P_{2}}\right)^{n}\right)^{2}}}{\left(1-\left(\frac{P}{P_{1}}\right)^{n}\right)+\frac{\left(\frac{P}{P_{1}}\right)^{n}\left(\frac{P}{P_{2}}\right)^{n}\left(1-\left(\frac{P}{P_{2}}\right)^{n N_{\mathrm{L}}}\right)}{\left(1-\left(\frac{P}{P_{2}}\right)^{n}\right)}}\right)
$$

The final expression of model 1 contained physicochemical parameters such as $n, N_{\mathrm{M}}, N_{\mathrm{L}}, P_{1}$, and $P_{2}$. These parameters are defined as follows: the number of molecules per site, $n$, the density of the receptor sites, $N_{\mathrm{M}}$, the number of adsorbed layers, $N_{\mathrm{L}}$. From the experimental isotherm, we deduced the pressures at the half-saturation, $P_{1}$ and $P_{2}$.

\subsection{Fitting results}

The main objective of the modeling process was to select the appropriate model that better correlated with the isotherm experimental data. The $\mathrm{CO}_{2}$ adsorption isotherms on activated
4.1.1 $n_{1}$ and $n_{2}$ parameters. The parameters $n_{1}$ and $n_{2}$, which represented the number of atoms per site, were stoichiometric coefficients. These parameters were in accordance

Table 3 Values for the $R_{2}$ fitting coefficient

\begin{tabular}{ll}
$T(\mathrm{~K})$ & $\begin{array}{l}\text { Monolayer with } \\
\text { fixed parameters }\end{array}$ \\
\hline 298 & 0.9964 \\
323 & 0.9973 \\
353 & 0.9980
\end{tabular}




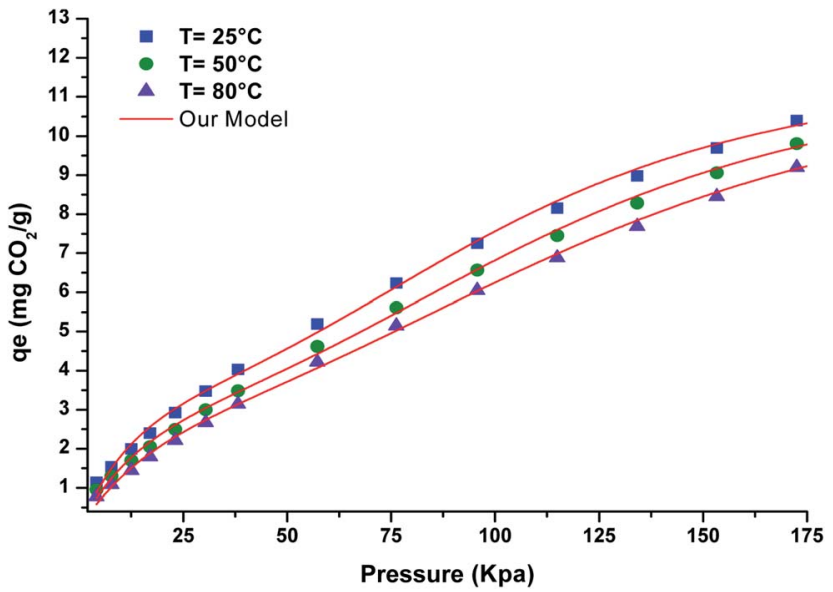

Fig. 6 Experimental data for the $\mathrm{CO}_{2}$ adsorption isotherms on activated clay fitted with our model.

Table 4 Adjustment parameter values corresponding to the best fit model

\begin{tabular}{lrrrrrl}
\hline $\begin{array}{l}\text { Temperature } \\
\left({ }^{\circ} \mathrm{C}\right)\end{array}$ & $\mathrm{NM}_{1}$ & $\mathrm{NM}_{2}$ & $P_{1}$ & $P_{2}$ & $n_{1}$ & $n_{2}$ \\
\hline 25 & 6.23 & 10.77 & 134.17 & 53.52 & 2.55 & 0.81 \\
50 & 1.73 & 8.48 & 130.30 & 49.55 & 3.16 & 0.916 \\
80 & 1.58 & 6.74 & 134.01 & 45.42 & 3.35 & 1.02
\end{tabular}

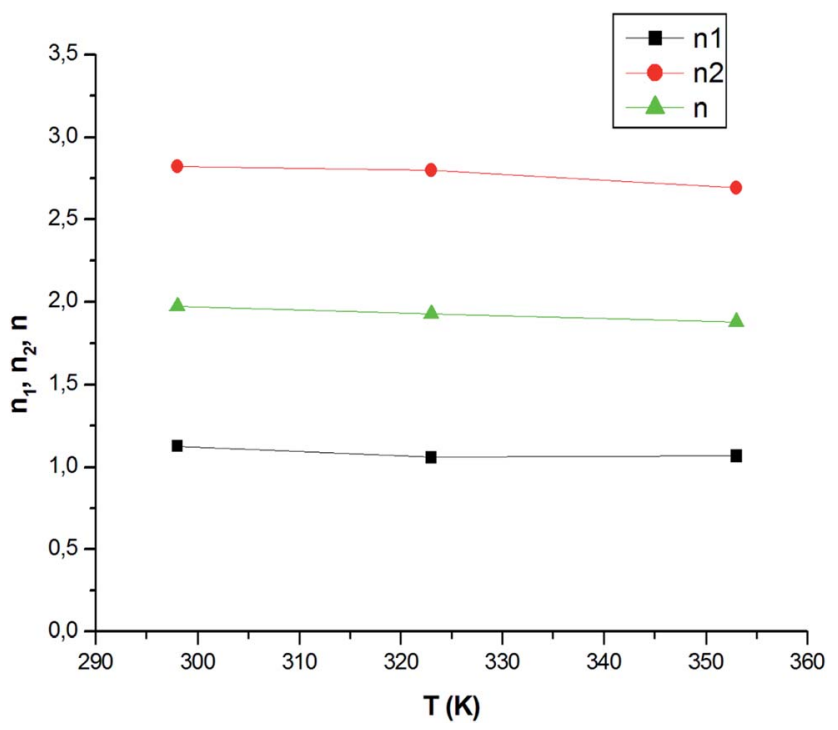

Fig. 7 Variation in the number of atoms per site $n_{1}$ and $n_{2}$ versus the temperature.

with the adsorption complexation expressed by eqn (1). The numbers $\left(n_{1}\right.$ and $\left.n_{2}\right)$ were integers. However, the adjusted values for $n_{1}$ and $n_{2}$ were not integers because these yielded the average values for all of the receptor sites, which could have been a decimal number. Fig. 7 shows the variation in $n_{1}$ and $n_{2}$ during the adsorption process. We noted that the values for the

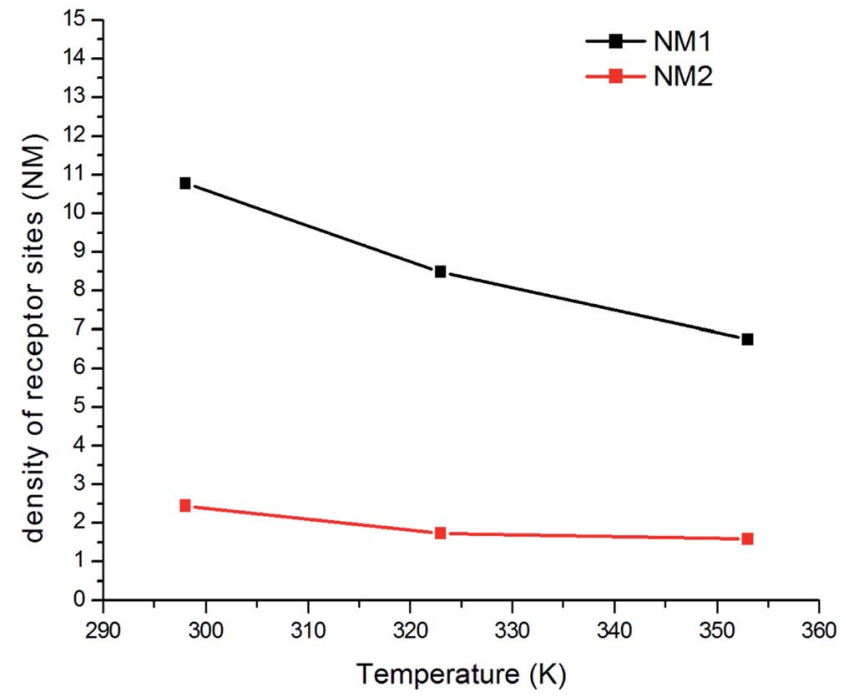

Fig. 8 Variation in parameters $\mathrm{NM}_{1}$ and $\mathrm{NM}_{2}$ versus the temperature.

number of $\mathrm{CO}_{2}$ atoms in the first and the second site were not identical during the adsorption phenomena. In addition, the number of molecules per site $(n)$ was defined as the average yield for all of the receptor sites, which ranged from 1.68 to 2.18 for all of the site types. The variation in $n$ was due to the effect of the temperature.

4.1.2 $\mathbf{N M}_{1}$ and $\mathbf{N M}_{2}$ parameters. The parameters $\mathrm{NM}_{1}$ and $\mathrm{NM}_{2}$ presented two receptor sites, which were actually necessary for activation to separately adsorb the atoms. The evolution of the $N_{1 \mathrm{M}}$ and $N_{2 \mathrm{M}}$ adsorption was a function of the temperature as shown in Fig. 8. We saw that these parameters evolved in an opposite manner than the temperature. The temperature lowered the $\mathrm{NM}_{1}$ and $\mathrm{NM}_{2}$ densities. The thermal agitation effect prevents the occupation of the sites, and therefore, reflects the exothermic effect of adsorption for both sites.

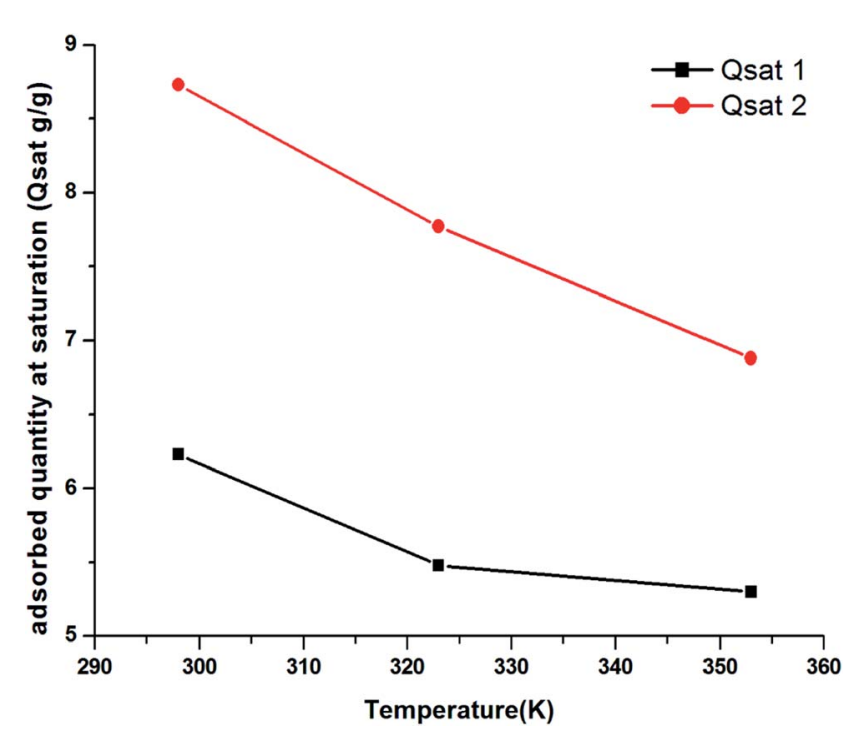

Fig. 9 Variation in parameters $Q_{\text {sat1 }}$ and $Q_{\text {sat2 }}$ versus the temperature. 
4.1.3 Saturation adsorption quantity $Q_{\text {sat }}$ parameters. The saturation adsorption quantity, $Q_{\text {sat }}$, depended on the number of molecules per site $(n)$ and the density of the NM receptor sites, which characterized the ability of the activated clay surface to capture the carbon dioxide molecules. ${ }^{16}$ We noted from Fig. 9 that an increase in the temperature led to a reduction in the adsorbed quantity during the first phase, $Q_{\text {sat1 }}$. The evolution of $Q_{\text {sat }}$ was consistent with the exothermic character of the $\mathrm{CO}_{2}$ adsorption process on the sample. In fact, we noted that the global adsorption was attributed to two separate contributions. Despite the difference in the site properties, the global filling was almost similar. Both sites belonged to the same unit form with a slightly larger padding requirement for the second type of site in the second phase. The maximum adsorbed $Q_{\text {sat }}$ increased with the increase in the temperature. The increase in $n_{2}$ was already attributed to the endothermic nature of the aggregation of $n_{2} \mathrm{CO}_{2}$ atoms on the $N_{2 \mathrm{M}}$ density of the receptor site.

\subsection{Energy parameters}

The energy adsorption was an important parameter used to characterize the nature of the interaction between carbon dioxide and the sample. From the parameters $P_{1}, P_{2}$, and the vapor saturation pressure, the adsorption energy $\Delta E_{1 \mathrm{a}}$ and $\Delta E_{2 \mathrm{a}}$ for site 1 and 2 was expressed by the following equation: ${ }^{21}$

$$
\Delta E_{1}=\Delta E^{\mathrm{V}}-R T \ln \left(\frac{P_{i}}{P_{\mathrm{vs}}}\right)
$$

where $i=1$ or 2 and $R$ is the ideal gas constant, $R=8.314472 \mathrm{~J}$ $\mathrm{mol}^{-1}$, and $P_{\mathrm{vs}}$ is the pressure of the saturated vapor.
Table 5 Values corresponding to the adsorption energies

\begin{tabular}{lll}
\hline$T(\mathrm{~K})$ & $\Delta E_{1}\left(\mathrm{~kJ} \mathrm{~mol}^{-1}\right)$ & $\Delta E_{2}\left(\mathrm{~kJ} \mathrm{~mol}^{-1}\right)$ \\
\hline 298 & 106.45 & 108.72 \\
323 & 129.47 & 132.60 \\
353 & 161.33 & 164.50
\end{tabular}

Fig. 10 shows the variation in the adsorption energies versus three temperatures $(298 \mathrm{~K}, 323 \mathrm{~K}$, and $353 \mathrm{~K})$ and Table 5 presents their value. $\Delta E_{1}$ and $\Delta E_{2}$ present the interaction between the molecules and the surface of the first and second layer, respectively. We saw that both adsorption energies increased with respect to the temperature. This was due to the effect of thermal agitation. The adsorption energy calculated at $298 \mathrm{~K}$ was $108.72 \mathrm{~kJ} \mathrm{~mol}^{-1}$, while the adsorption energy at $353 \mathrm{~K}_{\text {was }} 164.50 \mathrm{~kJ} \mathrm{~mol}^{-1}$. This increase in energy was explained by the temperature effect, which agitated the atoms in the site and possibly facilitated the adsorbed atoms to be easily lodged in the volume of the site.

\subsection{Entropy}

From the grand canonical partition function for the multilayer model with two energies, the entropy is expressed as follows: ${ }^{22}$

$$
\frac{S_{\mathrm{a}}}{k_{\mathrm{B}}}=-\beta \frac{\partial \ln \left(Z_{\mathrm{gc}}\right)}{\partial \beta}+\ln \left(Z_{\mathrm{gc}}\right)
$$

The adsorption entropy, $S_{\mathrm{a}}$, was calculated using the following expression:

$$
S_{\mathrm{a}}=k_{\mathrm{B}}\left[N_{1 \mathrm{M}} \ln \left(1+\left(\frac{x}{P_{1}}\right)^{n_{1}}\right)+N_{2 \mathrm{M}} \ln \left(1+\left(\frac{x}{P_{2}}\right)^{n_{2}}\right)\left(\frac{N_{1 \mathrm{M}}\left(\frac{x}{P_{1}}\right)^{n_{1}} \ln \left(\frac{x}{P_{1}}\right)^{n_{1}}}{\left(1+\left(\frac{x}{P_{1}}\right)^{n_{1}}\right)}+\frac{N_{2 \mathrm{M}}\left(\frac{x}{P_{2}}\right)^{n_{2}} \ln \left(\frac{x}{P_{2}}\right)^{n_{2}}}{\left(1+\left(\frac{x}{P_{2}}\right)^{n_{2}}\right)}\right)\right]
$$

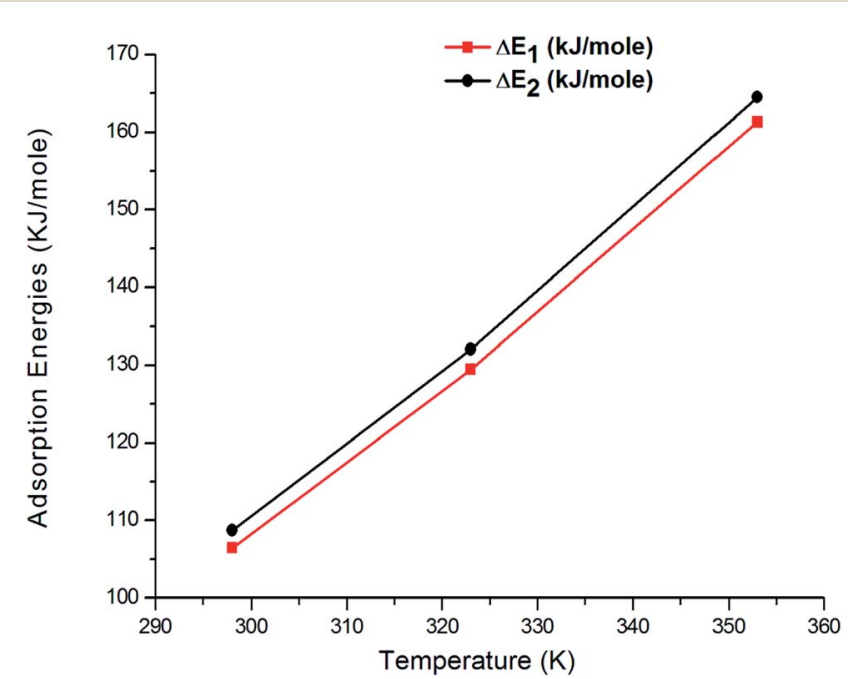

Fig. 10 Variation in adsorption energies $\Delta E_{1}$ and $\Delta E_{2}$ versus the temperature.

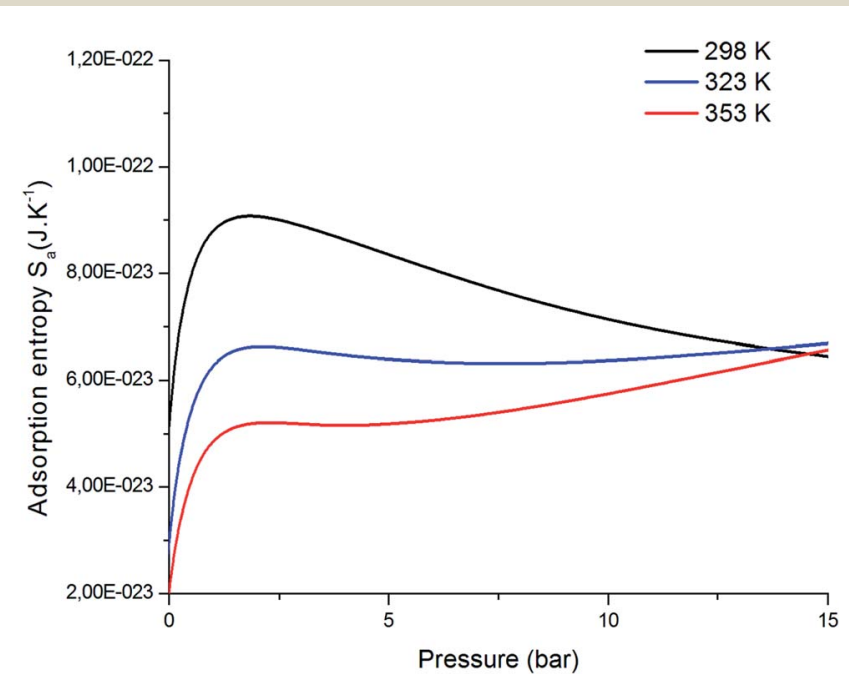

Fig. 11 Evolution of the entropy, $S_{a}$, versus the pressure at different temperatures. 
The entropy indicates the degree of disorder and randomness of $\mathrm{CO}_{2}$ molecules. Fig. 11 shows the evolution of entropy as a function of pressure at different temperatures. Indeed, at low pressures, the entropy increases; this is due to the availability of a large number of receptor sites on the surface of the adsorbent. Therefore, the $\mathrm{CO}_{2}$ molecules were connected to the empty sites. Then, at high pressures, we saw a reduction in the entropy configuration. This reduction was due to the decrease in the number of free sites. Consequently, at high pressures, $\mathrm{CO}_{2}$ had a low probability of selecting a receptor site since the adsorbent tended toward saturation, and therefore tended toward being ordered.

\subsection{Internal energy}

The internal energy is corresponding to the interactions between the adsorbate-adsorbent system. The internal energy is given by: ${ }^{23}$

$$
\begin{gathered}
E_{\mathrm{int}}=-\frac{\partial \ln \left(Z_{\mathrm{gc}}\right)}{\partial \beta}+\frac{\mu}{\beta}\left(\frac{\partial \ln Z_{\mathrm{gc}}}{\partial \mu}\right) \\
E_{\mathrm{int}}=k_{\mathrm{B}} T \ln \frac{\beta P}{Z_{\mathrm{g}}}\left(\frac{N_{1 \mathrm{M}}\left(\frac{x}{P_{1}}\right)^{n_{1}}}{\left(1+\left(\frac{x}{P_{1}}\right)^{n_{1}}\right)}+\frac{N_{2 \mathrm{M}}\left(\frac{x}{P_{2}}\right)^{n_{2}}}{\left(1+\left(\frac{x}{P_{2}}\right)^{n_{2}}\right)}\right) \\
-k_{\mathrm{B}} T\left(\frac{N_{1 \mathrm{M}}\left(\frac{x}{P_{1}}\right)^{n_{1}} \ln \left(\frac{x}{P_{1}}\right)^{n_{1}}}{\left(1+\left(\frac{x}{P_{1}}\right)^{n_{1}}\right)}+\frac{N_{2 \mathrm{M}}\left(\frac{x}{P_{2}}\right)^{n_{2}} \ln \left(\frac{x}{P_{2}}\right)^{n_{2}}}{\left(1+\left(\frac{x}{P_{2}}\right)^{n_{2}}\right)}\right)
\end{gathered}
$$

Fig. 12 shows the internal energy variation of $\mathrm{CO}_{2}$ adsorption depicted at different temperatures. We can see that the internal energy values are negative for all temperatures. Moreover, an increase in the pressure was observed, which in turn shows a decrease in the enthalpy. In this study, the decreases in enthalpy present the amount of work available to introduce the

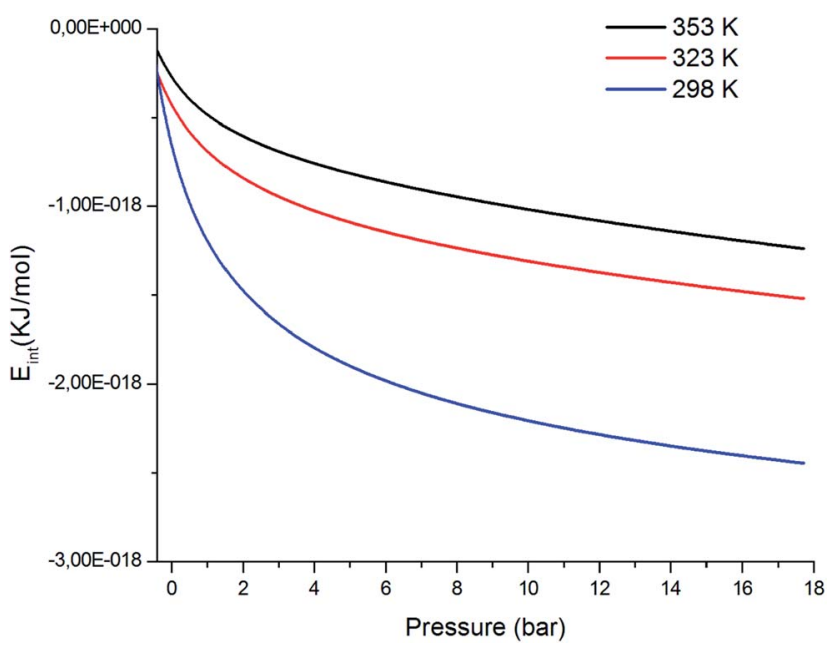

Fig. 12 Evolution of the internal energy, $E_{\text {int, }}$ versus the pressure at different temperatures.

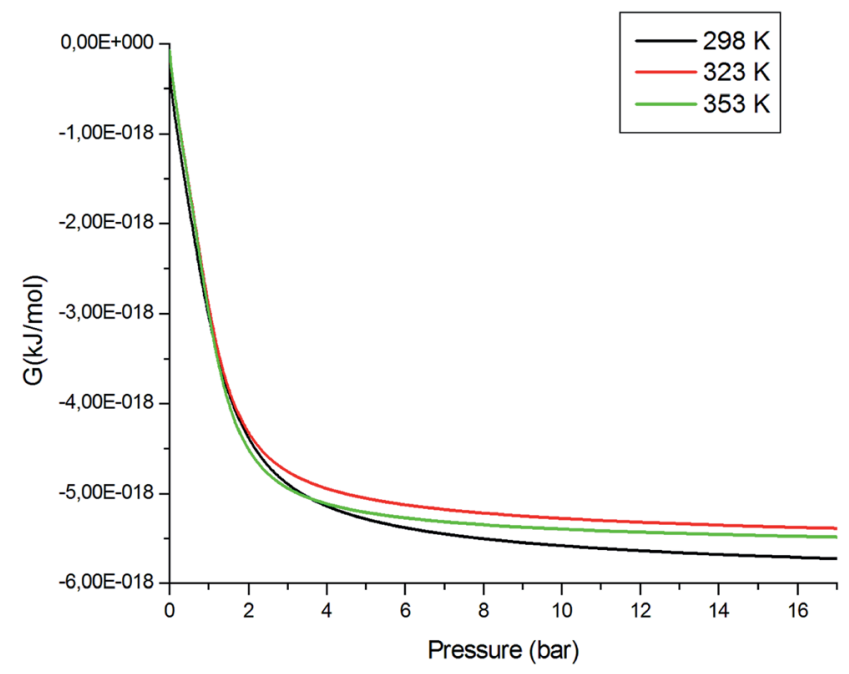

Fig. 13 Evolution of the Gibbs free energy versus pressure at different temperatures.

atoms $n_{1}$ and $n_{2}$ in the receptor sites $N_{1 \mathrm{M}}$ and $N_{2 \mathrm{M}}$. The adsorption process was exothermic in nature.

\subsection{Gibbs free energy}

The Gibbs free energy, $G$, describes the spontaneity of the system, and is given as follows: ${ }^{24}$

$$
G=\mu \times Q_{\mathrm{a}}
$$

Therefore, the expression for the Gibbs free energy is:

$$
G=k_{\mathrm{B}} T \ln \frac{\beta P}{Z_{\mathrm{g}}}\left(\frac{n_{1} N_{1 \mathrm{M}}}{n_{1} 1+\left(\frac{x}{P_{1}}\right)}+\frac{n_{2} N_{2 \mathrm{M}}}{n_{2} 1+\left(\frac{x}{P_{2}}\right)}\right)
$$

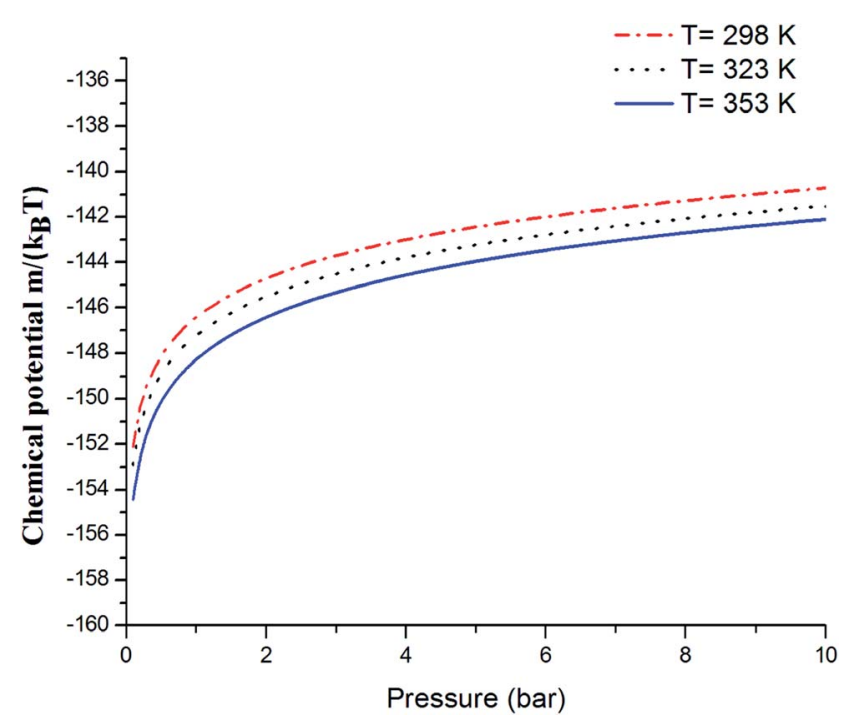

Fig. 14 The variation in the chemical potential with pressure. 
Fig. 13 shows the variation in the Gibbs free energy as a function of pressure for different temperatures. The Gibbs free energy, $G$, was negative, which reflected that the adsorption reaction was spontaneous. This thermodynamic function decreased with increasing temperature, which meant that the thermal agitation decreased the spontaneity of the adsorption process.

\subsection{Chemical potential}

The chemical potential is written as follows: ${ }^{24}$

$$
\mu=k_{\mathrm{B}} T \ln \frac{\beta P}{z_{\mathrm{g}}}
$$

Fig. 14 shows the evolution of the chemical potential versus the pressure. The chemical potential decreased with increasing temperature. Also, we noted that with an increasing temperature, the total number of adsorbed $\mathrm{CO}_{2}$ atoms decreased. On the other hand, if we augmented the pressure, the adsorption process progressed and the $\mathrm{CO}_{2}$ amount increased progressively in the adsorbent. Therefore, the chemical potential increased.

\section{Conclusion}

In this paper, the $\mathrm{CO}_{2}$ adsorption on activated clay was measured at different temperatures $(298 \mathrm{~K}, 323 \mathrm{~K}$, and $353 \mathrm{~K}$ ) and characterized via SEM, XRD, and $\mathrm{N}_{2}$ adsorption-desorption. The adsorbent was simulated using a statistical physics model. The parameters for the carbon dioxide adsorption isotherms were theoretically interpreted using the multi-layer model with two energies. The main characteristic parameters, namely, the number of carbon dioxide molecules per site $(n)$, the receptor site density (NM), and the energetic parameters $\left(-\varepsilon_{1}\right)$ and $\left(-\varepsilon_{2}\right)$, were interpreted at different temperatures. In fact, the thermodynamic functions, namely, the entropy, the Gibbs free energy, and the internal energy, were evaluated. The results showed that $\mathrm{CO}_{2}$ adsorption on activated clay was spontaneous and exothermic in nature.

\section{Conflicts of interest}

There are no conflicts to declare.

\section{Acknowledgements}

The authors would like to thank the USCR_Environmental for their Thermo Fisher FEI Q250 scanning electron microscope at the University of Monastir and for helpful technical assistance with equipment facilities.

\section{References}

1 A. Wahby, J. Silvestre-Albero, A. Sepúlveda-Escribano and F. Rodríguez-Reinoso, $\mathrm{CO}_{2}$ adsorption on carbon molecular sieves, Microporous Mesoporous Mater., 2012, 164, 280-287.

2 I. E. A., Energy technology perspectives, http://www.iea.org/ techno/etp/etp10/English.pdf, 2010.
3 H. Jedli, J. Brahmi, H. Hedfi, M. Mbarek, S. Bouzgarrou and K. Slimi, Adsorption kinetics and thermodynamics properties of Supercritical $\mathrm{CO}_{2}$ on activated clay, J. Pet. Sci. Eng., 2018, 166, 476-481.

4 P. R. Jeon, J. Choi, T. S. Yun and C.-H. Lee, Sorption equilibrium and kinetics of $\mathrm{CO}_{2}$ on clay minerals from subcritical to supercritical conditions: $\mathrm{CO}_{2}$ sequestration at nanoscale interfaces, Chem. Eng. J., 2014, 255, 705-715.

5 A. Guo, Y. Ban, K. Yang and W. Yanga, Metal-organic framework-based mixed matrix membranes: Synergetic effect of adsorption and diffusion for $\mathrm{CO}_{2} / \mathrm{CH}_{4}$ separation, J. Membr. Sci., 2018, 562, 76-84.

6 H. Jedli, A. Jbara, H. Hedfi, S. Bouzgarrou and K. Slimi, Carbon dioxide adsorption isotherm study on various cap rocks in a batchreactor for $\mathrm{CO}_{2}$ sequestration processes, Appl. Clay Sci., 2017, 136, 199-207.

7 J. L. Venaruzzo, C. Volzone, M. L. Rueda and J. Ortiga, Modified bentonitic clay minerals as adsorbents of $\mathrm{CO}$, $\mathrm{CO}_{2}$ and $\mathrm{SO}_{2}$ gases, Microporous Mesoporous Mater., 2002, 56, 73-80.

8 Y.-H. Chen and De-L. Lu, $\mathrm{CO}_{2}$ capture by kaolinite and its adsorption mechanism, Appl. Clay Sci., 2015, 104, 221-228.

9 Q. Lyu, X. Long, P. G. Ranjith, J. Tan, Y. Kang and Z. Wang, Experimental investigation on the mechanical properties of a low-clay shale with different adsorption times in sub-/ super-critical $\mathrm{CO}_{2}$, Energy, 2018, 15, 1288-1298.

$10 \mathrm{H}$. Jedli, Abdessalem Jbara. Hachem Hedfi. souhail Bouzgarrou. Khalifa Slimi. A laboratory study of supercritical $\mathrm{CO}_{2}$ adsorption on cap rocks in the geological storage conditions, Appl. Phys. A, 2017, 123, 254.

11 H. Jedli, J. Brahmi, H. Hedfi, M. Mbarek, S. Bouzgarrou and K. Slimi, Adsorption kinetics and thermodynamics properties of Supercritical $\mathrm{CO}_{2}$ on activated clay, J. Pet. Sci. Eng., 2018, 166, 476-481.

12 A. Gannouni, M. Bagane and A. Bellagi, $\mathrm{SO}_{2}$ adsorption onto activated clay, Ann. Chimie Sci. Matériaux, 1994, 19, 27-37.

13 S. Bouzgarrou, H. Jedli, N. Stiti, N. Hamdi, K. Slimi and M. Bagana, Experimental Adsorption and Modelisation of $\mathrm{CO}_{2}$ on adsorbents collected from elborma fieldin South Tunisia, J. Surf. Eng. Mater. Adv. Technol., 2015, 5, 52-63, DOI: $10.4236 /$ jsemat.2015.51006.

14 B. Diu, C. Guthmann, D. Lederer and B. Roulet, Physique Statistique, Hermann, Paris, 1989.

15 C. Briki, M. Bouzid, M. Houcine Dhaou, A. Jemni and A. Ben Lamine, Experimental and theoretical study of hydrogen absorption by $\mathrm{LaNi}_{3.6} \mathrm{Mn}_{0.3} \mathrm{Al}_{0.4} \mathrm{Co}_{0.7}$ alloy using statistical physics modeling, Int. J. Hydrogen Energy, 2018, 43(20), 9722-9732.

16 F. Aouaini, S. Bouzgarrou, N. Khemiri, M. Ben Yahia, E. S. Almogait, F. F. AlHarbi, A. H. Almuqrin and A. Ben Lamine, Study of the $\mathrm{CO}_{2}$ adsorption isotherms on El Hicha clay by statistical physics treatment: microscopic and macroscopic investigation, Sep. Sci. Technol., 2019, 54(16), 1-12.

17 B. Diu, C. Guthmann, D. Lederer and B. Roulet, Physique statistique, Hermann, Paris, 1989. 
18 S. Brunauer, L. S. Deming and E. Teller, On a theory of the van der Waals adsorption of gases, J. Am. Chem. Soc., 1940, 62, 1723-1732.

19 S. Bouzgarrou, H. Jedli, N. Stiti, N. Hamdi, K. Slimi and B. Mohamed, Experimental Adsorption and Modelisation of $\mathrm{CO}_{2}$ on Adsorbents Collected from Elborma Field in South Tunisia, J. Surf. Eng. Mater. Adv. Technol., 2015, 5, 52-63.

20 R. B. Anderson, Modifications of the Brunauer, Emmett and Teller equation, J. Am. Chem. Soc., 1946, 68(4), 686-691.

21 F. Aouaini, S. Knani, M. Ben Yahia and A. Ben Lamine, Statistical research of water vapor sorption isotherm in food materials: steric and energetic interpretations, Sens. Lett., 2015, 131, 1-10.
22 M. Hadi, M. R. Samarghandi and G. McKay, Equilibrium two-parameter isotherms of acid dyes sorption by activated carbons: study of residual errors, J. Chem. Eng. Data, 2010, 160, 408-416.

23 L. Couture and R. Zitoun, Physique statistique, Ellipses, 1992, p. 375.

24 (a) I. Rubinstein and L. Rubinstein, Partial differential equation in classical mathematical physics, The Hebrew University of Jerusalem, 1998, p. 18e64; (b) N. Bouaziz, M. Bouzid and A. Ben Lamine, Theoretical study of hydrogen absorption and desorption in Ti1-xZrx $\mathrm{Mn}_{1.4}$ using statistical physics treatment: Microscopic investigation and thermodynamic potential interpretation, Int. J. Hydrogen Energy, 2018, 43(3), 1615-1633. 